\title{
Over-the-scope clip (OTSC) reduces surgery rate in the manage- ment of iatrogenic gastrointestinal perforations
}

\section{다 (i)}

\author{
Authors \\ Sherine Khater, Gabriel Rahmi, Guillaume Perrod, Elia Samaha, Hedi Benosman, Leila Abbes, Georgia Malamut, \\ Christophe Cellier
}

\section{Institution}

Department of Gastroenterology and Digestive Endoscopy, Georges Pompidou European Hospital, Assistance Publique - Hôpitaux de Paris, Université Paris Descartes, Sorbonne Paris Cité, Paris, France

submitted 23.9.2016

accepted after revision 1.2.2017

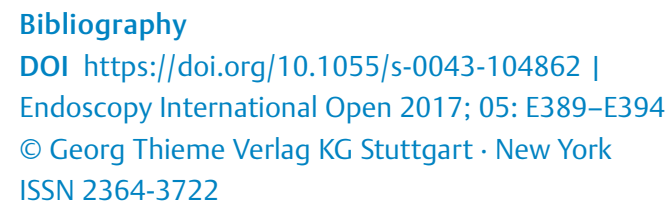

Corresponding author

Sherine Khater, MD, Department of Gastroenterology and Digestive Endoscopy, Georges Pompidou European Hospital, 20 rue Leblanc, 75015 Paris, France

Fax: +33-1-56-09-29-14

sherine_khater@hotmail.com

\section{ABSTRACT}

Background and study aims Over-the-scope clip (OTSC) has been recently used in management of gastrointestinal perforations, but data on it are still limited. The aim of this study was to compare management of iatrogenic perforations before and after the OTSC was available in our endoscopy unit.

Patients and methods We conducted a monocentric retrospective study from June 2007 to June 2015. All iatrogenic gastrointestinal perforations detected during endoscopy were included. Two time periods were compared in terms of surgery and mortality rates: before use of OTSC (June 2007 to June 2011) and after OTSC became available (June 2011 to June 2015).

Results During the first period, 24 perforations were recorded. Fifteen (62.5\%) were managed with surgery. The mortality rate was $8 \%$. During the second period, 16 perforations occurred. In 11 patients (68.7\%), an OTSC was used to close the perforation, with complete sealing of the perforation in $100 \%$ of cases. However, 2 patients with sigmoid perforation had to undergo surgery due to right ureteral obstruction by the clip in 1 case and to presence of a localized peritonitis in the other. The surgery rate during this period was $12.5 \%(2 / 16)$, with a statistically significant difference compared to the first period $(P=0.002)$. There was no mortality in the second period versus $8 \%$ in the first one $(P=0.23)$.

Conclusions OTSC is effective for endoluminal closure of iatrogenic perforations and results in a significant decrease in surgery rate.

\section{Introduction}

Perforation is one of the most serious complications of endoscopic procedures and is associated with a high rate of morbidity and mortality [1,2]. In most series, this complication occurs in less than $0.1 \%$ of diagnostic colonoscopies [3-5] and in 1 in 2500 to 1 in 11000 diagnostic upper gastrointestinal endoscopies [6]. Although currently low, the incidence of iatrogenic perforation has the potential to become a significant health problem given the increasing number of colonoscopies performed for screening purposes. Furthermore, therapeutic techniques such as endoscopic mucosal resection (EMR) and endoscopic submucosal dissection (ESD) are associated with higher complication rates relative to other basic endoscopic interventions; the reported perforation rates are $0.3 \%$ to $0.5 \%$ in EMR and $4 \%$ to $10 \%$ in $\operatorname{ESD}[7,8]$. Thus, management of iatrogenic perforation has received great attention in the last years in order to develop reliable and safe endoscopic closure techniques.

Through-the-scope (TTS) clipping devices have been used for nearly 20 years for closure of luminal perforations [9-11]; however, they have limited opening width and closure strength. Recently, a new over-the-scope clip (OTSC; Ovesco Endoscopy AG, Tubingen, Germany) has been developed. In contrast to common endoscopic clips, the OTSC is able to capture a larger volume of tissue with a higher compression force; thus it can be used for closure of luminal perforations larger than $10 \mathrm{~mm}$ [12]. Ex vivo experiments showed that the acute strengths of closed gastric, duodenal, and colonic perforations by using the OTSC were comparable with the gold standard of surgical suturing [13]. The superiority of OTSCs relative to TTS 
clips for closure of gastrointestinal perforations and natural orifice transluminal endoscopic surgery (NOTES) access points was reported in extensive animal trials [14-17]. Recently, case reports and small case series in humans have confirmed these promising results $[18,19]$. Since data from clinical use are still limited, we present our experience with OTSC in management of gastrointestinal perforations occurring during an endoscopic procedure. The aim of this study was to compare management of iatrogenic perforations before and after the OTSC was available in our endoscopy unit at a tertiary center.

\section{Patients and methods}

We conducted a retrospective study at the European Georges Pompidou Hospital from June 2007 to June 2015. All iatrogenic gastrointestinal perforations occurring during an endoscopic procedure and detected during the procedure were included in the study, irrespective of the perforation location. Delayed perforations were excluded. Perforation was defined as a complete disruption of the gastrointestinal wall, which was documented by an endoscopic view of extraintestinal structures. We started using OTSC in the management of perforations in June 2011. Thus, the study was divided into 2 equal periods of time:

- Period 1: before the use of the OTSC, from June 2007 to June 2011

- Period 2: during which the OTSC was available, from June 2011 to June 2015.

The OTSC system is composed of an applicator cap with a mounted nitinol clip, which is affixed to the tip of the endoscope, and a connected releasing mechanism installed on the handle of the scope. The diameters of the OTSC used in this study were $9 \mathrm{~mm}$ and $11 \mathrm{~mm}$. There are 3 types of clip according to the shape of the teeth: atraumatic (type a) with rounded teeth, traumatic (type t) with pointed teeth, and the gastric fistula closure (type gc) with longer pointed teeth. In this study, we only used the traumatic type with sharp teeth that improve tissue capture. In some cases, the edges of the perforation were approximated before the OTSC is released by using an endoscopic double-grasping forceps ("twin-grasper"). This device has 2 jaws that can be opened separately to grasp opposite edges of the defect sequentially and then pull them together to draw the tissue into the cap before clip deployment. In the other cases, the OTSC system was applied using suction force alone.

In both periods, all patients had multidisciplinary management involving gastroenterologists, surgeons and intensive care physicians. All patients were given antibiotics according to local guidelines.

The primary endpoint of the study was to compare the rate of surgery between the 2 groups. The secondary endpoints were to compare the mortality rates between the 2 groups and to determine the technical and the clinical success rate of the OTSC. Technical or procedural success was defined as the success in clip deployment, with adequate endoscopic closure of the perforation combined with absence of leakage. Clinical success was defined as a resolution of perforation and a favorable outcome without need for surgery within 30 days after endoscopic closure and without clip-related adverse events.

\section{Results}

\section{Period 1}

During the first period (from June 2007 to June 2011), 24 perforations were recorded for 29,203 endoscopies performed. Eighteen were located in the colon (of which 14 in the rectosigmoid and 4 in the right colon and caecum), 5 in the duodenum and 1 in the stomach. In half the cases, the perforation occurred during a diagnostic endoscopy, and in the other half it occurred during a therapeutic endoscopy. The mean age of the patients was 68 years [range $34-93$ years].

Fifteen of 24 patients with perforations (62.5\%) were immediately referred for surgery without any attempt at endoscopic treatment. Five of these patients had a temporary stoma. One patient died of complications related to surgery.

In 2 cases ( $4.1 \%)$, the perforation was closed with TTS clips and the outcome was favorable. In 7 patients (29.1\%), management was conservative with antibiotics, intravenous fluids, strict fasting and close observation and monitoring. This approach was chosen in patients with a small defect, a retroperitoneal perforation, an adequate bowel preparation, and absence of generalized peritonitis. One of these patients died after he developed generalized peritonitis and sepsis; he was not operated on because of very bad overall health.

\section{Period 2}

During the second period of the study (from June 2011 to June 2015), 16 perforations occurred in 35,525 endoscopies performed. Nine were located in the colon (of which 8 were in the rectosigmoid and 1 in the transverse colon), 4 in the duodenum, 2 in the stomach and 1 in the esophagus. Of the perforations, $56.2 \%$ occurred during therapeutic endoscopy. The mean age of patients in this period was 66.1 years [range 31-93 years].

Four patients were successfully treated with TTS clips. An average of 9 TTS clips was required for the closure of each perforation.

In 1 case, the perforation was located in the esophagus following bougienage for a caustic stricture and was treated with placement of a fully covered self-expandable metallic stent, with a favorable outcome. In 11 patients (68.7\%), an OTSC was used to close the perforation ( $\triangleright$ Fig. 1 and $\triangleright$ Fig. 2). After the perforation was detected, the endoscope was removed, fitted with a cap-mounted OTSC and reintroduced by using carbon dioxide insufflation only. The mean size of the perforation in these patients was $11.5 \mathrm{~mm}$ [10-20 mm]. A single OTSC was used in each case. The twin grasper was used in 4 patients to approximate the edges of perforation. Exsufflation of the pneumoperitoneum using an 18-gauge needle was performed by the endoscopist in 2 patients. The characteristics of these patients and the outcomes are summarized in $>$ Table 1. Technical success was achieved in $100 \%$ because all patients had adequate deployment of the OTSC and complete sealing of the per- 

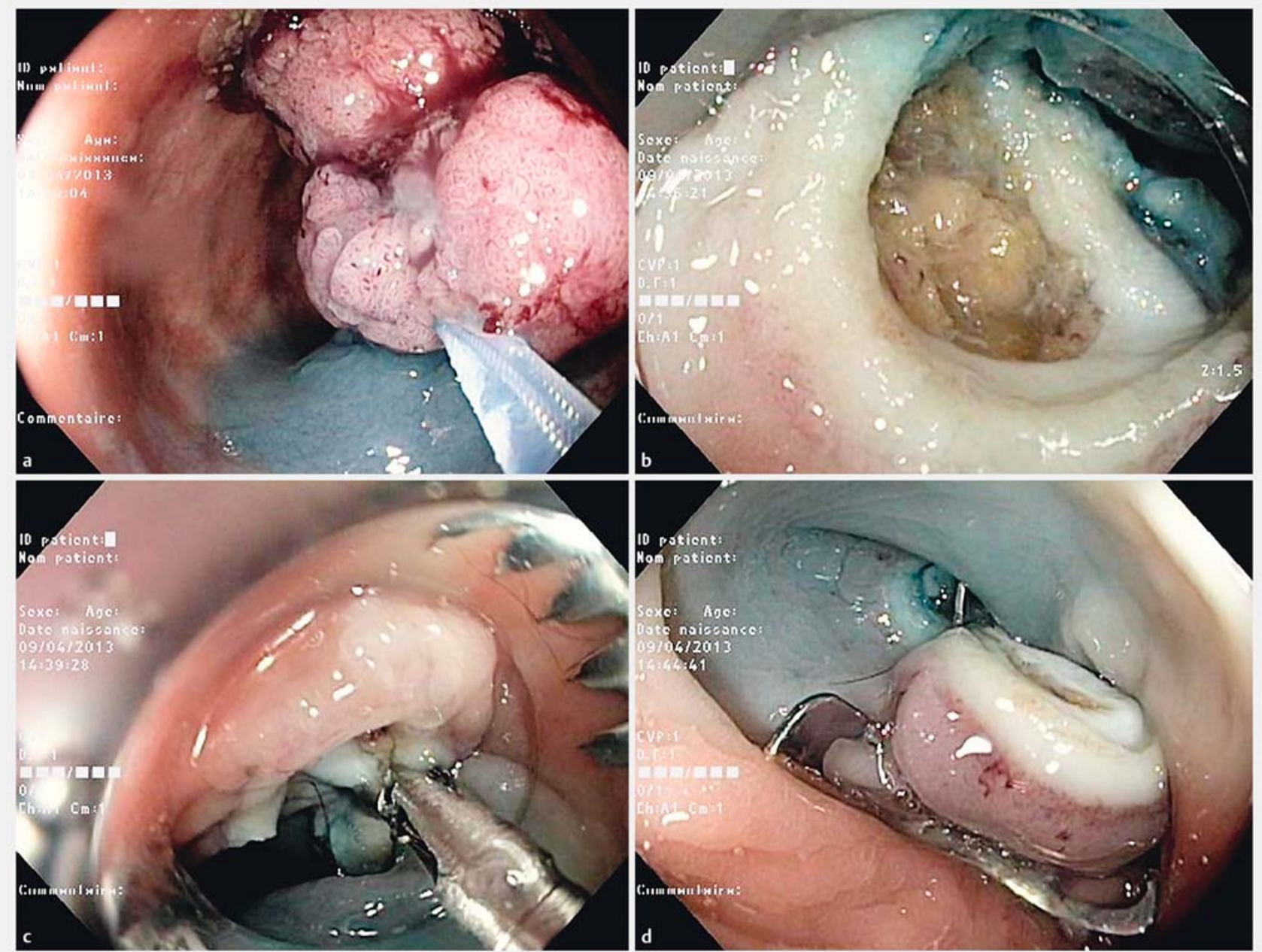

- Fig. 1 Endoscopic images from a patient who was treated with an OTSC. a An EMR in the sigmoid is complicated by b a perforation. c A twin grasper is used to approximate the edges of the perforation and $\mathbf{d}$ an OTSC is used to close the perforation.

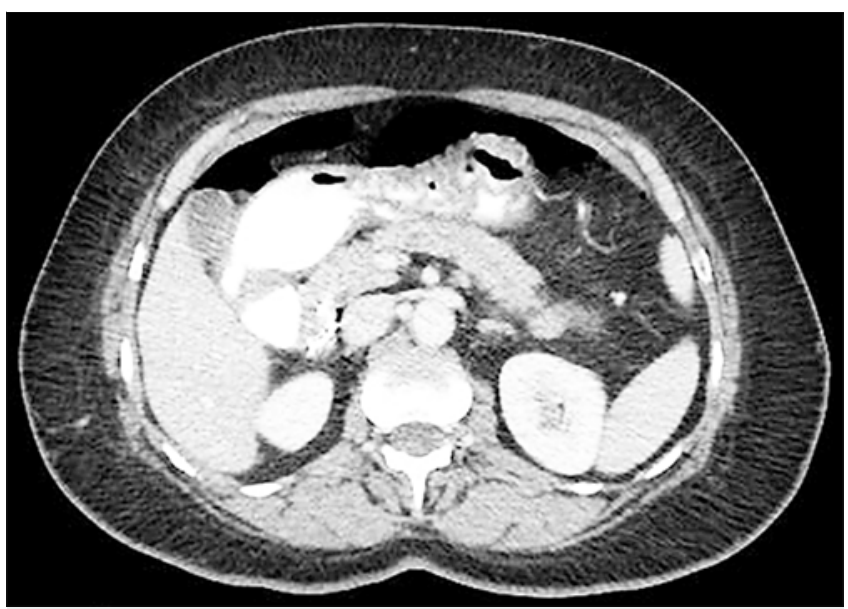

- Fig. 2 Abdominal CT scan performed 24 hours after a duodenal bulb perforation treated by OTSC placement. The clip is in the same location and the opacification with oral contrast shows no leakage. foration without leakage. The overall clinical success rate was $81.8 \%(9 / 11)$. Indeed, 2 patients had to undergo surgery despite adequate closure of the perforation. The first one (Case 1) had a perforation at the rectosigmoid junction during retroflexion in the rectum. A complete seal of the perforation was obtained with a single OTSC but in the following hours, the patient had abdominal pain with localized guarding in the left lower quadrant; thus, he underwent exploratory laparoscopy, which showed no leakage after injection of methylene blue. However, there was a purulent effusion in the peritoneal cavity and a sigmoid colostomy was performed. The clinical outcome was favorable after surgery. The second patient (Case 6) also had a perforation at the rectosigmoid during diagnostic colonoscopy. The perforation was managed by placement of an OTSC and exsufflation of the pneumoperitoneum using an 18gauge needle was performed during the procedure. A computed tomography (CT) scan 24 hours later showed a pneumoperitoneum and complete sealing of the perforation. However, the right urinary tract was dilated above the clip suggesting that the clip might have captured the right ureter. Another CT 
- Table 1 Characteristics and outcomes of patients treated with OTSC.

\begin{tabular}{|c|c|c|c|c|c|c|c|c|}
\hline Patient & Sex & Age & $\begin{array}{l}\text { Location of } \\
\text { perforation }\end{array}$ & Cause & $\begin{array}{l}\text { Perforation } \\
\text { size }\end{array}$ & $\begin{array}{l}\text { Use of twin } \\
\text { grasper }\end{array}$ & $\begin{array}{l}\text { Technical } \\
\text { success }\end{array}$ & $\begin{array}{l}\text { Clinical } \\
\text { success }\end{array}$ \\
\hline 1 & M & 81 & $\begin{array}{l}\text { Rectosigmoid } \\
\text { junction }\end{array}$ & $\begin{array}{l}\text { Diagnostic colo- } \\
\text { noscopy }\end{array}$ & $10 \mathrm{~mm}$ & No & Yes & $\begin{array}{l}\text { No (surgical } \\
\text { intervention) }\end{array}$ \\
\hline 2 & $\mathrm{~F}$ & 73 & $\begin{array}{l}\text { Colorectal } \\
\text { anastomoses }\end{array}$ & $\begin{array}{l}\text { Therapeutic colo- } \\
\text { noscopy (EMR) }\end{array}$ & $10 \mathrm{~mm}$ & Yes & Yes & Yes \\
\hline 3 & $\mathrm{~F}$ & 73 & Rectum & $\begin{array}{l}\text { Therapeutic colo- } \\
\text { noscopy (ESD) }\end{array}$ & $20 \mathrm{~mm}$ & Yes & Yes & Yes \\
\hline 4 & $\mathrm{~F}$ & 63 & Sigmoid & $\begin{array}{l}\text { Therapeutic colo- } \\
\text { noscopy (EMR) }\end{array}$ & $15 \mathrm{~mm}$ & Yes & Yes & Yes \\
\hline 5 & $\mathrm{~F}$ & 71 & Sigmoid & $\begin{array}{l}\text { Therapeutic colo- } \\
\text { noscopy (EMR) }\end{array}$ & $10 \mathrm{~mm}$ & No & Yes & Yes \\
\hline 6 & $\mathrm{~F}$ & 43 & $\begin{array}{l}\text { Rectosigmoid } \\
\text { junction }\end{array}$ & $\begin{array}{l}\text { Diagnostic colo- } \\
\text { noscopy }\end{array}$ & $10 \mathrm{~mm}$ & Yes & Yes & $\begin{array}{l}\text { No (ureteral } \\
\text { obstruction) }\end{array}$ \\
\hline 7 & $\mathrm{~F}$ & 92 & Sigmoid & $\begin{array}{l}\text { Diagnostic colo- } \\
\text { noscopy }\end{array}$ & $10 \mathrm{~mm}$ & No & Yes & Yes \\
\hline 8 & $\mathrm{~F}$ & 78 & Cardia & $\begin{array}{l}\text { Therapeutic gastro- } \\
\text { scopy (EMR) }\end{array}$ & $10 \mathrm{~mm}$ & No & Yes & Yes \\
\hline 9 & $\mathrm{~F}$ & 56 & Duodenal bulb & Diagnostic EUS & $10 \mathrm{~mm}$ & No & Yes & Yes \\
\hline 10 & $\mathrm{~F}$ & 78 & Duodenal bulb & Diagnostic EUS & $10 \mathrm{~mm}$ & No & Yes & Yes \\
\hline 11 & $\mathrm{~F}$ & 93 & Duodenum & Diagnostic EUS & $10 \mathrm{~mm}$ & No & Yes & Yes \\
\hline
\end{tabular}

scan was performed on the following day and confirmed right ureteral obstruction by the clip. The patient had to undergo surgery for ureteral resection and anastomosis and clip removal. The postoperative course was smooth.

- Table 2 summarizes the results from the 2 periods of the study.

\section{Comparison of the two periods}

The rate of surgery was $62.5 \%(15 / 24)$ in the first period of the study, and $12.5 \%(2 / 16)$ in the second period $(P=0.002)$.

The mortality rate was $8.3 \%(2 / 24)$ in the first period and $0 \%$ $(0 / 16)$ in the second period of the study, and this difference was not significant $(P=0.23)$

\section{Discussion}

Our experience has confirmed the results of previous studies and has shown favorable results with OTSC in closure of acute iatrogenic perforations that occur during endoscopic procedures. In the current series, technical success was achieved in $100 \%$ because all patients had adequate deployment of the OTSC and complete sealing of the perforation without leakage. The overall clinical success rate was $81.9 \%$ (9/11). The use of OTSC has improved management of iatrogenic perforation because the surgery rate decreased significantly after the clip became available (12.5\% vs $62.5 \%)$. There was no significant difference in mortality rate. No death occurred in the second period of the study.
The OTSC system is a relatively new technique that has been successfully used in treatment of gastrointestinal bleeding, perforations, anastomotic leak and fistulas. Its uses have been expanded to include prophylactic closure of large mucosal defects after ESD, resection of submucosal tumors and esophageal stent fixation [20]. At present, data are limited regarding its role in management of iatrogenic perforations occurring during endoscopic procedures. Most of the studies are small case series. Moreover, cases of perforations that are not endoscopy-related are usually included in these studies (for example: postoperative perforations, perforations caused by dislocated percutaneous endoscopic gastrostomie, and perforations occurring during percutaneous drainage of abdominal collection).

In a literature search conducted from January 2001 to August 2012, the overall success rate with OTSC was found to be in the range of $75 \%$ to $100 \%$ for closure of iatrogenic gastrointestinal perforations [21]. In a prospective trial including 36 patients with acute iatrogenic gastrointestinal perforations, immediate endoluminal closure was successful in $92 \%$ of cases and the overall clinical success rate was $89 \%$, with a mortality rate of $3 \%$. However, this prospective study included cases of perforations that were not endoscopy-related [18]. A recent multicenter retrospective study including 20 patients with iatrogenic gastrointestinal tract perforation treated by OTSC placement showed a clinical success rate of $90 \%$ with 2 patients having an incomplete sealing of the perforation with the clip 
- Table 2 Results from the 2 study periods.

\begin{tabular}{|c|c|c|}
\hline & Period 1 & Period 2 \\
\hline Number of perforations & 24 & 16 \\
\hline \multicolumn{3}{|l|}{ Location } \\
\hline - Colon & $18(75 \%)$ & $9(56.3 \%)$ \\
\hline - Duodenum & $5(20.8 \%)$ & $4(25 \%)$ \\
\hline - Stomach & $1(4.2 \%)$ & $2(12.5 \%)$ \\
\hline - Esophagus & 0 & $1(6.2 \%)$ \\
\hline \multicolumn{3}{|l|}{ Cause } \\
\hline - Diagnostic endoscopy & $12(50 \%)$ & $7(43.8 \%)$ \\
\hline - Therapeutic endoscopy & $12(50 \%)$ & $9(56.2 \%)$ \\
\hline - EMR & $5(20.9 \%)$ & 7 \\
\hline - ESD & 4 & 1 \\
\hline - Other (dilation...) & 3 & 1 \\
\hline \multicolumn{3}{|l|}{ Treatment } \\
\hline " Surgery & 15 & 9 \\
\hline " TTS clips & 2 & 4 \\
\hline - OTSC & 0 & $\begin{array}{l}11 \text {, with subse- } \\
\text { quent surgery in } 2\end{array}$ \\
\hline - Conservative management & 7 & 9 \\
\hline - Endoscopic stenting & 0 & 4 \\
\hline Surgery & $15(62.5 \%)$ & $2(12.5 \%)^{1}$ \\
\hline Mortality & $2(8.3 \%)$ & $0(0 \%)$ \\
\hline \multicolumn{3}{|c|}{$\begin{array}{l}\text { EMR, endoscopic mucosal resection; ESD, endoscopic submucosal dissec- } \\
\text { tion } \\
1 P<0.05\end{array}$} \\
\hline
\end{tabular}

[22]. No study has compared the rate of surgery before and after use of OTSC.

OTSC is a safe technique. In our study, 1 adverse event (AE) occurred due to the capture of the right ureter along with the gastrointestinal wall [23]. This complication should prompt us to be cautious when pulling the wall defect to the cap opening by suction before clip release. New devices are needed for removal of the OTSC clip when it is misplaced. An endoscopic instrument that cuts the OTSC at 2 opposing sites (DC ClipCutter; Ovesco Endoscopy) has been shown to be a feasible technique for removal of the OTSC [24]. The use of Nd:YAG-Laser was reported in 3 cases and requires further validation [25]. A prototype instrumentation that is designed to locally melt the clip by applying an electrical current pulse onto the clip structure has been evaluated in an animal study with promising results [26]. Use of a guidewire has also been shown to be a feasible technique for removing the OTSC in an ex vivo porcine model [27].

The main limitation of this study is the small number of patients included. However, it is difficult to have larger series because perforation is not a frequent complication of gastrointestinal endoscopy. Large multicenter studies are necessary to in- clude more patients. Furthermore, not all iatrogenic perforations can benefit from an endoscopic treatment; endoscopic closure should be considered depending on the type of the perforation, its size, the general clinical condition of the patient and the endoscopist expertise available at the center.

\section{Conclusion}

In conclusion, although the clinical experience with it is still limited, the OTSC system is effective for endoluminal closure of acute iatrogenic perforations occurring during diagnostic or therapeutic endoscopy. It results in a significant decrease in surgery rate. AEs are rare but caution is warranted especially when pulling the wall defect to the cap opening by suction because anatomical structures near the gastrointestinal wall can be trapped in the clip. Based on our experience, all endoscopy units should have a supply of OTSC, with a proper training for endoscopists and nurses on its use.

\section{Competing interests}

None

\section{References}

[1] Lohsiriwat V. Colonoscopic perforation: Incidence, risk factors, management and outcome. World J Gastroenterol 2010; 16: 425-430

[2] Lüning TH, Keemers-Gels ME, Barendregt WB et al. Colonoscopic perforations: a review of 30,366 patients. Surg Endosc 2007; 21: 994- 997

[3] Ko CW, Dominitz JA. Complications of colonoscopy: magnitude and management. Gastrointest Endosc Clin N Am 2012; 20: 659-671

[4] ASGE Standards of Practice Committee. Complications of colonoscopy. Gastrointest Endosc 2011; 74: 745-752

[5] Arora G, Mannalithara A, Singh G et al. Risk of perforation from a colonoscopy in adults: a large population-based study. Gastrointest Endosc 2009; 69: 654-664

[6] ASGE Standards of Practice Committee. Adverse events of upper GI endoscopy. Gastrointest Endosc 2012; 76: 707-718

[7] ASGE Technology Committee, Kantsevoy SV, Adler DG, Conway JD. Endoscopic mucosal resection and endoscopic submucosal dissection. Gastrointest Endosc 2008; 68: 11 - 18

[8] Taku K, Sano Y, Fu KI et al. Iatrogenic perforation associated with therapeutic colonoscopy: A multicenter study in Japan. J Gastroenterol Hepatol 2007; 22: 1409-1414

[9] Mangiavillano B, Viaggi P, Masci E. Endoscopic closure of acute iatrogenic perforations during diagnostic and therapeutic endoscopy in the gastrointestinal tract using metallic clips: A literature review. J Dig Dis 2010; 11: $12-18$

[10] Kim JS, Kim BW, Kim Jl et al. Endoscopic clip closure versus surgery for the treatment of iatrogenic colon perforations developed during diagnostic colonoscopy: a review of 115,285 patients. Surg Endosc 2013; 27: $501-504$

[11] Magdeburg R, Collet P, Post $S$ et al. Endoclipping of iatrogenic colonic perforation to avoid surgery. Surg Endosc 2008; 22: 1500 - 1504

[12] Baron TH, Wong Kee Song LM, Zielinski MD et al. A comprehensive approach to the management of acute endoscopic perforations (with videos). Gastrointest Endosc 2012; 76: 838-859 
[13] Voermans RP, van Berge Henegouwen MI, Bemelman WA et al. Novel over-the-scope-clip system for gastrotomy closure in natural orifice transluminal endoscopic surgery (NOTES): an ex vivo comparison study. Endoscopy 2009; 41: 1052-1055

[14] von Renteln D, Schmidt A, Vassiliou MC et al. Endoscopic closure of large colonic perforations using an over-the-scope clip: a randomized controlled porcine study. Endoscopy 2009; 41: 481-486

[15] Schurr MO, Hartmann C, Ho CN et al. An over-the-scope clip (OTSC) system for closure of iatrogenic colon perforations: results of an experimental survival study in pigs. Endoscopy 2008; 40: 584 - 588

[16] Matthes K, Jung Y, Kato M et al. Efficacy of full-thickness GI perforation closure with a novel over-the-scope clip application device: an animal study. Gastrointest Endosc 2011; 74: 1369-1375

[17] von Renteln D, Vassiliou MC, Rothstein RI. Randomized controlled trial comparing endoscopic clips and over-the-scope clips for closure of natural orifice transluminal endoscopic surgery gastrotomies. Endoscopy 2009; 41: 1056-1061

[18] Voermans RP, Le Moine O, von Renteln D et al. CLIPPER Study Group. Efficacy of endoscopic closure of acute perforations of the gastrointestinal tract. Clin Gastroenterol Hepatol 2012; 10: 603-608

[19] Hagel AF, Naegel A, Lindner AS et al. Over-the-scope clip application yields a high rate of closure in gastrointestinal perforations and may reduce emergency surgery. J Gastrointest Surg 2012; 16: 2132 - 2138
[20] Singhal S, Changela K, Papafragkakis H et al. Over the scope clip: technique and expanding clinical applications. J Clin Gastroenterol 2013; 47: 749-756

[21] Weiland T, Fehlker M, Gottwald T et al. Performance of the OTSC System in the endoscopic closure of iatrogenic gastrointestinal perforations: a systematic review. Surg Endosc 2013; 27: 2258-2274

[22] Mangiavillano B, Caruso A, Manta R et al. Over-the-scope clips in the treatment of gastrointestinal tract iatrogenic perforation: A multicenter retrospective study and a classification of gastrointestinal tract perforations. World J Gastrointest Surg 2016; 8: 315-320

[23] Rahmi G, Barret M, Samaha E et al. Ureteral obstruction after colonoscopic perforation closed with an over-the-scope clip. Gastrointest Endosc 2015; 81: $470-471$

[24] Schmidt A, Riecken B, Damm M et al. Endoscopic removal of over-thescope clips using a novel cutting device: a retrospective case series. Endoscopy 2014; 46: 762 - 766

[25] Fähndrich M, Sandmann M, Heike M. Removal of over the scope clips (OTSC) with an Nd:YAG Laser. Z Gastroenterol 2011; 49: 579-583

[26] Schostek S, Ho CN, Melbert M et al. DC current pulses for OTSC clip fragmentation: technology and experimental study. Surg Endosc 2015; 29: $2418-2422$

[27] Neumann H, Diebel H, Monkemuller K et al. Description of a new, endoscopic technique to remove the over-the-scope-clip in an ex vivo porcine model (with video). Gastrointest Endosc 2012; 76: 1009 1013 